\title{
"Children of the Dream" Revisited: 70 Years of Collective Early Child Care in Israeli Kibbutzim
}

\author{
Ora Aviezer, Marinus H. Van IJzendoorn, Abraham Sagi, and Carlo Schuengel
}

\begin{abstract}
This article focuses on kibbutz care for infants and young children. It reviews (a) past and present practices of collective education within the context of its historical background and guiding principles and (b) the results of developmental research regarding the impact of multiple caregiving and group care on children's socioemotional development within the framework of attachment theory. The research results indicate that, from a psychological point of view, collective sleeping is a problematic aspect of kibbutz child rearing. However, group care and multiple caregiving of high quality do not necessarily interfere with the formation of close relationships between parents and children or with the development of social skills.
\end{abstract}

An Israeli kibbutz (pl., kibbutzim) is a cooperative, democratically governed, multigenerational community with an average population of 400-900 people. Each kibbutz is economically and socially autonomous but is also affiliated with one of three kibbutz organizations called "kibbutz movements" that offer support and guidance to individual kibbutzim. In the past, the kibbutz movements were deeply divided by political and ideological differences that were expressed even on the level of child-care practices. With the passage of time, however, most of these differences have lost their significance, and many kibbutz members today favor the idea of establishing a single united kibbutz movement. Every kibbutz member works for the kibbutz economy and is in turn provided by the community with housing, food, clothing, health and educational services, recreation, and other living needs. In the past, kibbutzim had been fairly isolated agricultural communities in which living conditions were exceedingly hard. Today kibbutz economies are based on a diversity of industries and agricultural activities and are able to provide members with a satisfying standard of living.

The kibbutz is known as being one of the very few utopian experiments that have succeeded in establishing a radically different way of living and of raising children. As many as four generations have been brought up in kibbutzim since the first such communities were founded at the turn of the century. The kibbutz child-rearing system, also called collective education, has been treated in the literature as furnishing a "natural labo-

Ora Aviezer, School of Education of the Kibbutz Movement, Oranim, Israel, and Laboratory for the Study of Child Development, University of Haifa, Haifa, Israel; Marinus H. Van IJzendoorn and Carlo Schuengel, Center for Child and Family Studies, Leiden University, Leiden, The Netherlands; Abraham Sagi, Laboratory for the Study of Child Development, University of Haifa, Haifa, Israel.

Writing of this article was facilitated by a PIONEER grant (PG5 59256) awarded to Marinus H. Van IJzendoorn by the Netherlands' Organization for Scientific Research.

Correspondence concerning this article should be addressed to Ora Aviezer or Abraham Sagi, Laboratory for the Study of Child Development, University of Haifa, Haifa 31905, Israel. ratory" for testing the consequences of child-rearing methods that derived from a unique philosophy and from practices markedly different from those used in the West (Beit-Hallahmi \& Rabin, 1977; Bettelheim, 1969; Rapaport, 1958; Spiro, 1958).

Our goal in this article is to evaluate the positive and negative aspects of collective child rearing, particularly in regard to the socioemotional consequences for young children. We begin with a short review of the historical roots of the kibbutz movement and the guiding principles of collective education. This is followed with a description of educational practices in the past and of the changes that brought kibbutz child care to its present form. Then, in the second part of the article, the results of studies on kibbutz children are reviewed within the context of dynamic changes in kibbutz life both recently and in the past and with reference to developmental research. Particular emphasis is given to attachment relationships and their consequences. Finally, the development of social competence and relationships with peers is reviewed and discussed.

\section{Historical Background}

The early pioneers of the kibbutz movement were idealistic young people who rejected the culture of the shtetl that had dominated the life of Eastern European Jews for centuries and sought to create instead a new society founded on socialist and Zionist principles (Melzer, 1988; Selier, 1977). The task they set for themselves was in no way minor. They proposed to create a collective society that emphasized production and physical labor, striving at the same time to achieve both national and personal independence under conditions of perfect equality. The Marxian precept "from each according to his ability, to each according to his needs" was established as the primary and essential principle of kibbutz life. The political aspirations of kibbutzniks dictated their settlement in remote locations, where they were constrained to cultivate barren land in a harsh climate and a hostile environment. In these circumstances, the decision to raise children collectively contributed to the protection and well-being of the young. Children were thus housed in the only 
brick building on kibbutz grounds and never went hungry, whereas the adults of the community lived in tents and their food was rationed. Early in kibbutz history, this reality interacted with an awareness of the role of child rearing in furthering the goals of the collective by discouraging individualism, abolishing inequalities between the sexes, and bringing up a person who was better socialized to communal life (Gerson, 1978).

One of the principal goals of early kibbutzim was to alter the patriarchal organization of the family that was typical of Eastern European Jewish culture; in this culture, women were economically dependent on men and parental authority over children was absolute. Collective education was assigned an important place in achieving this goal. It was instituted so as to free women from the burdens of child care, thereby allowing them to participate in the socioeconomic life of the community on an equal footing with men. Men, on the other hand, would share in the duties of child care and become nurturing rather than authoritarian figures in the lives of their children. Moreover, bringing children up collectively was regarded as essential in fostering the solidarity of the group and restraining individualistic tendencies in both children and adults. Educational practices in kibbutzim were accordingly established so as to reflect the egalitarian and democratic philosophy of the kibbutz community (Gerson, 1978).

The kibbutz community therefore assumed total responsibility for all of the material needs of its children in the way of food, clothing, and medical care and for seeing to their spiritual wellbeing, the latter including mental health, developmental progress, and parental counseling (Gerson, 1978). This responsibility extended to each child individually, who was in a sense regarded as being a "kibbutz' child"; and it also created an informal communal socialization network (Rabin \& Beit-Hallahmi, 1982). Thus, child care and education were, first and foremost, conceived of as being social mechanisms. It was only later that the needs of children became a central concern in the consciousness of the community (Alon, 1976) and that kibbutzim tended to assume the character of a "child-centered community" (Lewin, 1990; Rabin \& Beit-Hallahmi, 1982) in which psychological theory came to influence educational conceptualizations and practices (Kaffman, Elizur, \& Rabinowitz, 1990).

\section{The Guiding Principles of Collective Education}

During the formative years of collective education, psychoanalytic theory was eagerly adopted as an educational guide. A token of this influence is already apparent in the work of Bernfeld, a reforming pedagogue whose utopian visions were widely accepted among young German Jews who immigrated to Palestine and joined the kibbutz movement (Melzer, 1988). Given that one of the principal goals of the kibbutz founders was to change family relations, it is not surprising that psychoanalytic views about the pathological consequences of conflicts in parent-child relations should have had a special appeal for them (Lavi, 1984, 1990a). Kibbutz educators interpreted these views as furnishing support for the ideas of dividing the task of socialization between parents and educators (caregivers and teachers) and of nonreliance on parents alone in educating infants and young children. Maintenance of two emotional centers for kib- butz children-the parental home and the children's housewas thought to protect children against their parents' shortcomings while preserving the benefits of parental love (Golan, 1959). The practice of having children sleep away from the parental home was justified on the grounds that it spared them from the trauma of exposure to the so-called "primal scene" and from the conflicts with parents that are imminent in the Oedipus complex (Golan, 1959).

Observers of the kibbutz have characterized parental involvement as emotional and directed toward need gratification, whereas caregivers have been described as being goal directed and instrumental (Bar-Yosef, 1959; Rabin \& Beit-Hallahmi, 1982). This role division was considered to be beneficial for children because the objective attitudes and professional approach of caregivers were conducive to the children's mastery of autonomous behavior and social learning without in any way compromising their parents' love (Gerson, 1978; Golan, 1958). In addition, living among peers from an early age was regarded as being an inseparable part of bringing up future kibbutz members because it presented children with a supportive environment for dealing with the kind of human values perceived to be at the core of kibbutz life, such as sharing and consideration for others (Hazan, 1973).

\section{Collective Education in Practice: Past and Present}

There has never been a simple one-to-one correspondence between child-rearing practices on kibbutzim and the beliefs of adult members. Socioeconomic and physical conditions, as well as new psychoeducational theories, have always had an impact on how kibbutz children are brought up, and ideological differences have existed between the different kibbutz organizations since their foundation. Individual kibbutzim, moreover, adopted day-to-day practices that accommodated their particular needs and the prevailing emotional atmosphere of the community (Lavi, 1990a). It is nevertheless possible to describe the practices that are typical of a collective kibbutz upbringing and to present these practices from a dynamic perspective of historical changes.

\section{Past Trends}

Before the 1940s, the medical model dominated approaches to child care both inside and outside the kibbutz (Gerson, 1978; Lewin, 1986). Cleanliness was maintained in infant houses to the point of sterility, infant feeding was rigorously scheduled, parental visits were restricted, and caregivers (Hebrew: s. metapelet, pl. metaplot) were trained in hospitals (Lewin, 1986). Caregivers were regarded as the experts and the ultimate authority in kibbutz children's care (Gerson, 1978). Characteristically, a very small staff of two or three caregivers took care of a large group of between 12 and 18 children. Some of these early practices can be better understood when one takes into account the ecological context of kibbutzim at the time; these were isolated communities far from medical facilities. Moreover, because of the prevalence of serious diseases in this pioneering period, the major concern was to keep babies alive, which was indeed managed quite successfully by the kibbutzim (Gerson, 
1978). These years were naturally difficult for many families, some of whom left the kibbutz.

After World War II and Israel's War of Independence, the emphasis shifted from physical health to the emotional needs of children and mothers. This change was supported by a gradual improvement in economic conditions and the increasing influence of the conceptualizations of Bowlby (1951) and Spitz (1946) in regard to "maternal deprivation," which replaced both the medical model and classical psychoanalysis (Lavi, 1984). Parental participation in child care through the infant's ist year, particularly on the part of mothers, was also allowed to increase. Mothers were granted maternity leave, which over the years was expanded from 6 weeks to a period of 3 or 4 months. In addition, demand feeding replaced schedule feeding, and breast-feeding was encouraged. As a result of changes that evolved in the $1970 \mathrm{~s}$, infants no longer live in the infant house on arrival from the hospital but remain at home with their mothers for the duration of maternity leave (Kaffman et al., 1990). Daily visits of mothers were instituted in the early 1960 s for the purpose of allowing mothers to spend time with their children (this period was humorously referred to as the "love hour"). The growing awareness in kibbutzim that children need intimacy for their emotional growth, as well as space and stimulation for activity, has been translated into improvements of the physical environment in the children's houses, a reduction of the size of groups to 4-7 children, and an improvement in the caregiver to children ratio. Training of caregivers has shifted its emphasis to developmental knowledge, educational practices, and the caregiver's role in supporting children's emotional development as it is expressed in tasks such as weaning, toilet training, and nocturnal fears (Lewin, 1985).

In the late $1960 \mathrm{~s}$, under the influence of Piaget's theory, children's cognitive development was emphasized (Lewin, 1985). Piaget's views of development as a product of interactions between children and their environment were easily accommodated by the egalitarian philosophy of collective education. The nature of children's activity, creativity, and play became the center of attention, as well as age-related curricula (e.g., Haas, 1986; Lewin, 1983).

\section{Collective Sleeping Arrangements}

Collective sleeping arrangements for children away from their parents constitute probably the most distinctive characteristic of kibbutz practices in collective child raising. Many cultures practice multiple caregiving (e.g., Barry \& Paxton, 1971; Konner, 1977; Morelli \& Tronick, 1991; Tronick, Winn, \& Morelli, 1985 ), and the pattern is in many ways similar to the practice in kibbutzim (Rabin \& Beit-Hallahmi, 1982). However, a worldwide sample of 183 societies showed that none of them maintained a system of having infants sleep away from their parents (Barry \& Paxton, 1971). The major reasons for instituting collective sleeping for children in the early years of kibbutzim were (a) the concern for children's safety, and (b) women's equality and training children for communal life (Fölling-Albers, 1988b; Lavi, 1984). These aims were later interpreted by kibbutz educators as concordant with fundamental psychoanalytic ideas. Thus, kibbutzim had created a psychological ideol- ogy that was used to justify collective sleeping arrangements as contributing to the children's well-being as well as mental health.

The children's house on a kibbutz in fact functions as the children's home in almost every respect. Only a few kibbutzim still maintain communal sleeping arrangements for children; in those where the custom continues, however, this facility serves as the place in which children spend most of their time, eat their meals, are bathed, and sleep at night, in much the same way as they might do at home-hence the term "children's house." The children's house is designed to fulfill all such functions. It consists of a number of bedrooms that are each shared by three or four children, a dining area, showers, and a large space for play activities and learning. Children have private corners in their bedrooms where they keep their personal things, and these corners are decorated according to the child's preference. Family time is in the afternoon and evening, when both parents try to be available. Children are returned to the children's house for the night by their parents, who put them to bed; a caregiver or a parent then remains with them until the night watchwomen take over.

Two night watchwomen are responsible for all children in the kibbutz under 12 years of age. The women are assigned on a weekly rotation basis, and they monitor the children's houses from a central location, usually the infant house, by making rounds and through the use of intercoms. In most cases, night watchwomen are not complete strangers to the children (BenYaakov, 1972). However, the weekly rotation system makes sensitive response to the infants' needs nearly impossible. Moreover, intervention by an unfamiliar adult when infants experience distress may elicit a response of stranger anxiety (Bronson, 1968; Spitz, 1965). Thus, although collective sleeping may allow for sufficient monitoring of children's safety, it leaves children with only a precarious and limited sense of security, Independent support for this view was recently offered in a study that found that the longest period of uninterrupted sleep (defined as the longest continuous period scored as sleep without any identified awakening) was more extended for children sleeping at home than for children in communal dormitories (OphirCohen, Epstein, Tzischinsky, Tirosh, \& Lavie, in press). It should be noted that this measure of sleep was derived from the recently developed Automatic Scoring Analysis Program conducted on actigraphic data (Sadeh, Lavie, Scher, Tirosh, \& Epstein, 1991). On the basis of the same actigraphic technique of data collection and analysis, Epstein (1992) recently compared sleeping patterns in 1-6-year-old kibbutz children when they slept collectively with their sleeping patterns at home 1 year later. The findings showed that sleep efficiency (defined as the ratio of sleep to total sleep time) in collective sleeping is low and that it improved when children were moved to sleep at home to a level of efficiency similar to that of family-reared children. This improvement occurred despite overcrowding in kibbutz family homes that had not yet been adapted to accommodate the children on a permanent basis. A more detailed discussion of this topic follows in a later section.

Most kibbutzim had abandoned collective sleeping by the beginning of the 1990s (this practice is currently in effect in only 3 of the country's 260 kibbutzim). Doubts about children's col- 
lective sleeping had been voiced as early as in the 1950 s, and a small number of kibbutzim have always maintained homebased sleeping arrangements (Lavi, 1984). The movement to change children's sleeping arrangements gained momentum in the 1960s and 1970s, along with an upsurge in familistic tendencies (Fölling-Albers, 1988b; Tiger \& Shepher, 1975). This trend was reinforced by the growing prosperity of kibbutz economies, which resulted in the building of better family homes for members on the one hand and the weakening of ideological identifications of young kibbutz members on the other (Lavi, 1990b). Familistic trends accelerated significantly in the 1980s, as had been predicted by some researchers (e.g., Beit-Hallahmi, 1981; Rabin \& Beit-Hallahmi, 1982). Moreover, these trends have continued, notwithstanding serious economic problems that required many kibbutzim to commit themselves to heavy financial obligations to be able to make the necessary modifications for family housing (Melzer \& Neubauer, 1988).

The success of familism in kibbutzim reduced women's participation in community life (Gerson, 1978; Lavi, 1984), pushing their struggle for equality into the background. Collective education failed to free kibbutz women from child care as their primary responsibility or from leading a dual-career life combining motherhood and work. Frustrated by their work options, many kibbutz women invested in motherhood (Keller, 1983), and women were the leading proponents for changing the practice of collective sleeping for children. Thus, along with the men, they helped to preserve the sex-typed occupational structure of kibbutzim (e.g., the absence of men in the caregiver's role), rather than attemptıng to change it (Fölling-Albers, 1988a).

\section{Present Practices}

Kibbutz infants are exposed to multiple caregiving very early in their lives (Lavi, 1990a). In their first 3 months, kibbutz infants receive exclusive maternal care in the family's residence. They are brought to the infant house as soon as their mothers return to work part time. During the initial period of their stay in the infant house, they are cared for jointly by the mother and the metapelet. Mothers are almost exclusively in charge of feeding, and they arrange their work schedule accordingly; caregivers are responsible for the infants between maternal visits. During the second half of the infants' 1st year, caregivers gradually assume responsibility for the children's various needs as the mothers increase their work load. Thus, by the infants' 2nd year, they come under the full care of the caregivers, who play an increasingly larger role in their socialization with respect to issues such as table manners, sharing, play habits, and knowledge of the environment.

Table 1 contains an overview of the caregiving responsibilities during early childhood in the kibbutz. This description represents a summary of various periods; the delegation of responsibilities may change further.

Children join the toddler group, which is larger than the infant group (10-12 children), at about the middle of their 2 nd year, but the 1:3 ratio of adults to children is maintained. At this stage, caregivers are responsible for a wide range of the children's needs (e.g., administering of medication, toilet training,

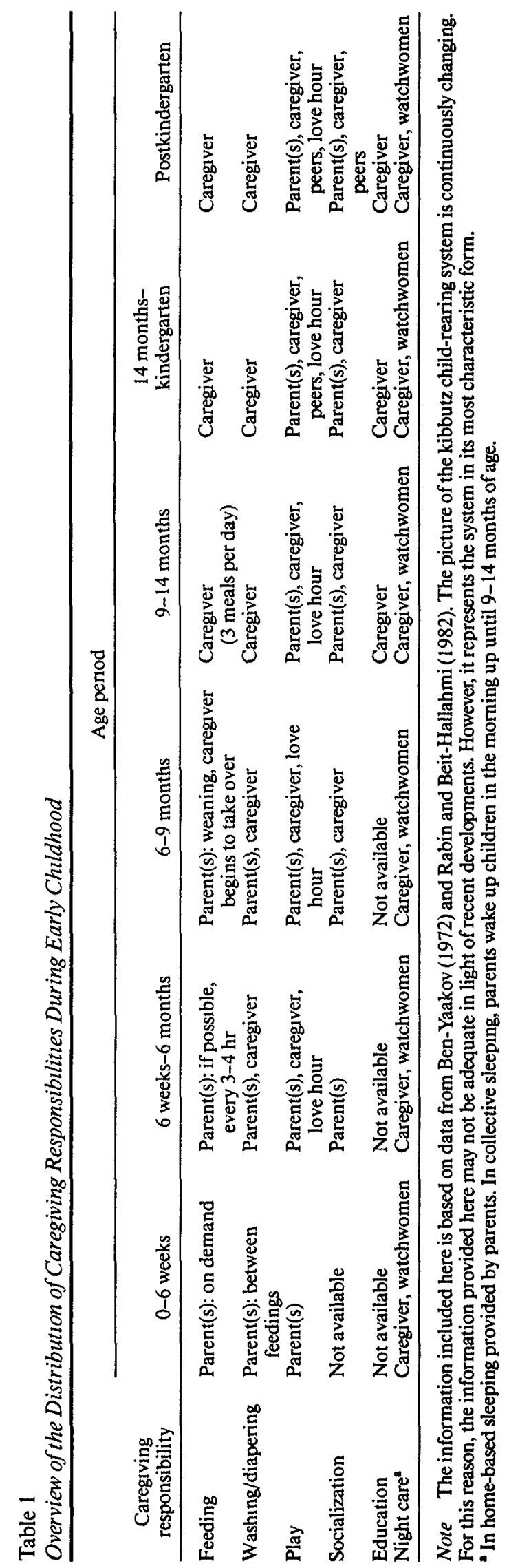


appropriate nutrition, and growth and age-appropriate activities of individual children). When children approach 3 years of age, they move to the nursery class, which is somewhat larger and where the ratio of adults to children is reduced to 1:4. Parents are welcome to spend time in the children's house; they visit whenever they can, and caregivers try to accommodate them.

Home-based sleeping has changed the proportion of time spent by kabbutz children in the children's house to a pattern similar to that of nonkibbutz day-care settings. Children come to the children's house in the morning and go home during late afternoon. Maternal responsibilities for infants' care throughout the 1st year have remained the same, but the love hour practice is no longer officially observed. Most parents, even among those originally opposed to home-based sleeping, are now satisfied with the change in sleeping arrangements (Lavi, 1984). Children's sleeping at home has clearly changed the balance between the two emotional centers of the family and the community. The family has become the principal authority and has assumed additional caregiving functions, whereas the caregivers' influence has declined and become secondary. Thus, a process is taking place in which responsibilities are being redefined, although the sense of the community's commitment to its children has been preserved.

Collective education in the 1990 s is therefore faced with the need of negotiating new ways of expressing the influence of the collective without infringing on the autonomy and privacy of families. This is not an easy task, considering the heterogeneous nature of multigenerational kibbutz populations. Also, recent economic difficulties and difficulties in providing adequate professional manpower have resulted in demands to reduce the costs of early care by restructuring it to resemble nonkibbutz day care in Israel (Sagi \& Koren-Karie, 1993). Clearly, early child care in kibbutzim is changing. As in the past, the changes are taking place within the context of general processes in which collective responsibility is being reduced and new ideas for the accountability of the community for the actions of individual members and the resultant consequences are being negotiated. This topic is, however, beyond the scope of the present article.

\section{Summary of the Historical Review}

The kibbutz approach to child rearing established a radically different method of raising children that was legitimized by both socialist and psychoanalytic ideas. Its original conceptualization as a social mechanism for promoting the goals of a new society led to the institution of unique child-care practices. More specifically, the practices of nonmaternal care for infants and toddlers, children dwelling with their peers in children's houses instead of with their families, and the division of the tasks of socialization between parents and caregivers (teachers) differed markedly from the educational practices common in Western societies (see Lamb, Sternberg, Hwang, \& Broberg, 1992; Melhuish \& Moss, 1991).

The course of the evolution of early care in kibbutzim reflects the changes occurring in the physical and socioeconomic conditions of these communities, as well as changes in ideology, educational conceptualizations, and knowledge. During the early period of kibbutzim, collective education was, in part, determined by the difficult conditions of existence; thus, children's health and physical development were regarded as the primary criteria for child care. The rigors of the environment, adherence to the medical model, inexperience and lack of knowledge, and ideological zeal all contributed to the strict practices involving kibbutz children and their parents. Growing knowledge about young children's emotional and cognitive development and improved economic conditions later led to a shift in emphasis to emotional needs and to a restructuring of early care in kibbutz education. The definition of children's well-being thus came to include more than mere physical health and resulted in an emphasis on caregiving practices and furnishing children with a stimulating environment.

A historical overview of early child care in the kibbutz reveals an important shift in the relative weights assigned to the two major agents of socialization: the family and the community. In the beginning, the influence of the community was preeminent. Thus, its representatives-the caregivers-were granted ultimate authority over educational practices. In later years, there has been a gradual ascendancy of familism, expressed by more intense parental involvement. The institution of home-based sleeping has finalized the process by transferring most caregiving functions to the family. The practice of collective sleeping arrangements for children, which is rapidly disappearing, has become a historically unique phenomenon that deserves an evaluation in terms of its socioemotional consequences.

\section{The Kibbutz System of Early Care: A Research Review}

As noted earlier, child rearing in kibbutzim has attracted a fair amount of attention motivated by interest in the developmental outcomes of its unique practices. Any comprehensive system such as kibbutz child care can be evaluated from a variety of points of view. In what follows, we briefly consider studies of parental attitudes, caregivers' roles, and the quality of care offered by collective education. We then evaluate in depth the developmental consequences of kibbutz child rearing, with an emphasis on socioemotional development.

\section{Parental Attitudes}

A hypothesis frequently proposed about kibbutz mothers is that their lower than usual participation in the care of their children may result in guilt feelings that lead to insecure motherchild relationships (e.g., Fölling-Albers, 1988b; Liegle, 1974). According to Bettelheim (1969), however, kibbutz women suffer from maternal guilt feelings because of their subconscious rejection of their own mothers. No empirical evidence corroborates either of these claims. Lewin (1990) found that most kibbutz mothers regard the infant house and metapelet as assisting them in their motherhood. However, women's prominent support of familistic trends suggests that recent generations of mothers lay claim to a larger share in the caregiving role than did mothers in the founding generations of the kibbutzim (Kaffman et al., 1990; Lavi, 1984; Spiro, 1979; Tiger \& Shepher, 1975). Kibbutz mothers entertain specific notions about themselves in the role of educators. They perceive themselves as be- 
ing more nurturant and influential in the development of interpersonal behavior in their children. They attribute to the metapelet a more demanding role and regard themselves as less influential than her in regard to such age-related behaviors as dressing and toilet training. In comparison, day-care mothers perceive themselves as being more nurturant and influential than caregivers in every domain of child development (Feldman \& Yirmiya, 1986).

\section{The Role of Caregivers}

Caregivers are assigned a central role in kibbutz education. Their influence on children's development of autonomy and socialization to kibbutz life is considered paramount, and their constant and stable presence is thought to potentially compensate for poor maternal functioning (Gerson, 1978). Indeed, metaplot have been reported to perceive themselves as the most important influence in children's social development and physical care (Kaffman et al., 1990); however, they have also been reported to be uncertain about their professional role when mother-infant relations require intervention (M. Harel, 1986). The trust kibbutz mothers have expressed in their infants' caregivers (Feldman \& Yirmiya, 1986; Lewin, 1990) has been attributed to the sharing of responsibilities and the openness of kibbutz child-care services to parental and community supervision (Feldman \& Yirmiya, 1986) and to the professional expertise of caregivers (M. Harel, 1986). Like kibbutz mothers, most metaplot (who are often mothers themselves) have been supportive of home-based sleeping and of infants remaining with their mothers for more extensive periods after their birth (Kaffman et al., 1990).

Systematic observations of caregivers' interactions with toddlers have shown that the approach of metaplot toward children is positive but is adversely affected by poor physical conditions and caregivers' fatigue (Gerson \& Schnabel-Brandes, 1990). Gerson and Schnabel-Brandes suggested that the metaplot's strong commitment to the ideological and pedagogical values of the kibbutz and their strong involvement with the children contributed to their positive approach. However, Rosenthal (1991) found that superior training and experience rather than ideological commitment distinguished kibbutz metaplot from caregivers in other Israeli day-care settings.

\section{Quality of Early Care in the Kibbutz}

In a recent overview of Israeli day-care centers by Sagi and Koren-Karie (1993), the quality of kibbutz child care was rated as being the best in the country. The specific advantages indicated by these authors were the high quality of the physical and educational environment in the kibbutz system, the small group size (8-12 children), a good caregiver to child ratio (1:3$1: 4)$, and the high level of caretakers' commitment. Note that these standards of care had developed in the kibbutz long before the quality of nonmaternal care had become an issue of professional concern, and their advantage had already become evident. For instance, Gewirtz (1965) attributed the decline of smiling he found among infants from institutions and day nurseries, as compared with infants reared in families and kibbut- zim, to less stimulation and availability of caregivers in those child-care settings in which custodial care and poor children to adult ratios prevailed.

Rosenthal (1991) examined three Israeli child-care settings in regard to the educational quality of the physical environment, the content and emotional tone of each program, and the characteristics of the daily interactions of the children with their caregivers. Her findings corroborated Sagi and Koren-Karie's (1993) assessment. The kibbutz environment was significantly better than the environment of both center care and family day care. Emotional atmosphere and children's daily interactions in the kibbutz resembled those in family day care, in which group size and adult-child ratio are similar. However, kibbutzim scored significantly better in these respects than did center care. In addition, children's social orientation and active learning are determined by developmentally appropriate activities, which are another aspect of quality caregiving (Howes, Phillips, \& Whitebook, 1992; Rosenthal, 1991). Rosenthal (1991) also measured the extent to which toddlers in the various settings engaged in active learning and social interaction as an indication of the quality of their experience. She found that kibbutz children were more active in both learning and social exchanges and attributed this finding to their experience in an environment that combined structural aspects and processes of better quality care as delineated by Phillips and Howes (1987).

Yet, caregivers' stability, which is another important aspect of quality care, seems to be a relative weakness in the kibbutz child-care system. Gerson and Nathan (1969) surveyed the entire caregiver population of the kibbutz movement and found a $25 \%-33 \%$ annual turnover rate. Caregiver turnover rates were highest for toddler groups and lowest for infant groups. Although no current data are available on the topic, Lewin (1982) reported that caregiver turnover has always been a problem and has not decreased over the years. Turnover rates are related to the quality of a caregivers' work environment, the position often being characterized by low salaries and low prestige (Whitebook, Howes, \& Phillips, 1989). It is interesting to note that caregiving does not have much prestige in kibbutzim either, despite proclaimed convictions concerning its importance (Gerson \& Nathan, 1969). A possible reason is that early care is often regarded as a task that women can perform instinctually without formal training (Gerson, 1976). Although turnover rates reported for kibbutzim are somewhat lower than those in the United States (Whitebook et al., 1989), they are nevertheless high enough to suggest substantial instability. In a comprehensive system of care - such as that found in kibbutzim - that delegates many parental tasks to caregivers, the consequences of such instability may be even more severe. Yet, the cohesive, intimate nature of the kibbutz community, with its high degree of familiarity and involvement among people, may contribute to a sense of consistency and predictability for both children and parents. The sharing of caregiving responsibilities may be viewed as a source of instability in the children's house. However, unlike other child-care environments, kibbutz caregiving takes place within the context of enduring relationships. These relationships, in turn, can sustain adults' mutual trust (Feldman \& Yirmiya, 1986) and support children's sense of living in a stable, secure environment (see Rabin, 1965). One can con- 
clude that the quality of kibbutz care has been excellent in regard to its structural dimensions and basic caregiving characteristics; at the same time, however, caregiver stability has been relatively weak and may therefore have had adverse effects on children's socioemotional development (Howes et al., 1992).

\section{The Developmental Consequences of Kibbutz Child Rearing}

In this section, we consider the research on the developmental consequences of kibbutz child rearing, which has been in force for more than 4 decades. Classical evaluations of kibbutz child rearing were based on participant observation techniques and clinical impressions that focused on nonmaternal care for small children. Succeeding research efforts concentrated on comparing kibbutz children with their counterparts outside the kibbutz on measures that have often furnished global assessments of development, with implications for future personality characteristics. Exposure to multiple relationships in early childhood, which is inherent in group care, became the main issue in this regard. The current wave of research has been concerned with the socioemotional development of kibbutz children and has focused on attachment theory. Within the context of a growing worldwide prevalence of nonmaternal and group care in early childhood, studies have concentrated on the effects of the unique characteristics of collective upbringing on interpersonal relations and personality formation.

\section{Classical Evaluations of Kibbutz Child Rearing}

The general impression of most early observers of kibbutz children was that their relations with their parents were warm and affectionate; however, the delegation of child-care functions to caregivers was judged to be a potential obstacle to the formation of exclusive relationships between mothers and infants and a potential impediment for future personality development (Bettelheim, 1969; Irvine, 1952; Spiro, 1958; Winograd, 1958). However, both Spiro (1958) and Bettelheim (1969) concluded that kibbutz children appeared to grow into well-functioning and adapted adults, despite early indications of emotional insecurity (Spiro, 1958) and some interference with the development of personal identity, emotional intimacy, and individual achievement (Bettelheim, 1969).

Spiro (1958) observed, in an anthropological study, that kibbutz children often felt rejected by their caregivers and had to face aggression from their peers. Their emotional pain resulted in introversion and resistance in their interpersonal contacts with kibbutz members and outsiders. However, Spiro did not perceive the reality of kibbutz children as similar to institutions in which emotional deprivation prevails (Bowlby, 1951). Bettelheim (1969) believed that the "children of the dream," as he called kibbutz children, would experience early in their childhood a balanced mixture of trust and distrust of the environment. The relatively large number of caregivers would be a source of distrust, but the availability of caregivers in all situations and the continuous presence of the peer group would prevent the development of separation anxiety. According to Bettelheim, the absence of extremely positive or negative emotions in the experience of kibbutz children underlies an "emotional flatness" that he observed in their personalities. Unfortunately, many of the early observations were unsystematic (some were even based on secondhand reports) and often relied on small unrepresentative samples without control groups. Hence, they have been criticized as anecdotal and speculative (Lavi, 1990a; Rabin \& Beit-Hallahmi, 1982).

\section{The Early Studies}

The first systematic empirical investigation of the effects of collective child rearing was conducted by Rabin $(1958,1965)$. Rabin compared the performance of kibbutz children of various ages with that of children from a rural semicommunal setting (moshav) on a battery of tests of mental and social development to assess the hypothesis that kibbutz children suffer from partial psychological deprivation because of their repeated transitions between the parental home and the children's house. His results indicated a significant developmental lag in the socioemotional and verbal learning of kibbutz infants, although it was not considered to be pathogenic. This lag was found to have disappeared by 10 years of age, when there was evidence of early independence and less problematic puberty (Rabin, 1965). These results highlighted the differential effects of group environment in regard to multiple interpersonal relations at different ages. Although the presence of multiple "significant others" in infancy may be overwhelming to the tender personality, it may be supportive of ego development later in middle childhood and adolescence.

Rabin's work was, however, faced with various criticisms. Golan (1958) argued that the developmental delay found in kibbutz infants did not result from maternal deprivation. He attributed it to the caregivers' focus on satisfying infants' physical needs at the expense of providing them with personal contact and arranging adequate environment for play. Furthermore, Kohen-Raz (1968) criticized Rabin's sample as small and unrepresentative. He studied a larger sample of infants and found that the developmental level of kibbutz infants was equal to that of family-raised Israeli infants and to that of an American normative sample. In addition, contradictory findings of new studies challenged Rabin's conclusions about kibbutz infants. Gewirtz (1965) found that the smiling response of kibbutz infants through the first 18 months was similar to that of family-raised infants. Greenbaum and Landau (1977) found that kibbutz infants possessed advanced linguistic skills comparable to those of family-reared infants in spite of less time spent with their mothers; Holdstein and Borus (1976) found the same for kibbutz preschoolers. It was therefore concluded that collective education had no adverse effects on infant development (KohenRaz, 1968), and the nurturing, stimulating character of the kibbutz environment was underscored (Holdstein \& Borus, 1976).

Rabin's (1965) findings represented the development of kibbutz infants as observed during the 1950 s, when his study had been conducted. Because Rabin did not assess the quality of child care as a variable separate from interpersonal relationships, it would be difficult to argue that one or the other was an exclusive cause. Moreover, it is important to note that most of the early studies used developmental measures that evaluated 
social-verbal learning rather than socioemotional experience. Thus, given the wide consensus that the quality of day care is an important factor in children's development (Clarke-Stewart, 1989; Fein \& Fox, 1988; Howes, 1988b), it is not surprising that improvements in the quality of early child care in the kibbutz were associated with improved performance on developmental measures; these measures do not, however, allow for direct assessment of emotional development.

\section{Long-Term Effects of Collective Early Care}

Long-term effects are an important aspect of the consequences of early care. Kibbutz children, adolescents, and young adults have been judged to be emotionally healthy, constructive, and successful. Rabin (1965) based these conclusions on projective psychological tests (e.g., Rorschach, Draw a Person, Sentence Completion, and Thematic Apperception Test) in which he found indications of intellectual achievements, greater personality maturity, and ego strength. Also, Zellermayer and Marcus (1971) noted the scarcity of delinquency and drug abuse. In one of the few longitudinal studies of kibbutz-raised individuals, Rabin and Beit-Hallahmi (1982) interviewed Rabin's (1965) subjects 20 years after they had originally been studied. They found that collective-raised and moshav-raised adults were very similar in terms of their level of education and achievements. Furthermore, they were found to be similar in their functioning as spouses and in their identification with their parents. However, Rabin and Beit-Hallahmi also found some empirical support for a lower capability among kibbutz-reared adults to establish intimate friendships. This was attributed to the differential effect of the early experiences of the two groups. Similarly, a reduced need for affective involvement and emotional intimacy, as assessed by the Family Relations Test (Anthony \& Bene, 1957), was found by Regev, Beit-Hallahmi, and Sharabany (1980) among school-aged children and by Weinbaum (1990) among kindergartners who lived in kibbutzim with communal sleeping arrangements. Berman (1988) summarized a number of studies that investigated the effects of traditional collective upbringing (including communal sleeping) and concluded that such an upbringing had an impact on personality development by causing "a consistent interference with emotional experience, creativity, and the quality of object relations as expressed especially in intimate relationships" (p. 327). Thus, although it is generally agreed that kibbutz children grow up to become well-functioning adults, the findings indicate that they experience less emotional intensity in interpersonal relations, possibly as a result of their experiences in infancy. However, a direct assessment of the emotional experience of infants in collective child care and its consequences had to await new theoretical formulations and research procedures of the kind offered by attachment theory.

\section{Attachment Research: \\ Infants' Relationships and Their Consequences}

Bowlby's (1951) publication on maternal deprivation, as well as the work of researchers such as Spiro, Rabin, and Bettelheim, inspired changes in kibbutz child-care practices (Lavi, 1984).
Still, the primary research orientation was that of classical psychoanalytic theory, and it was not until the 1970s and 1980s that attachment theory became one of the leading paradigms. The conceptual framework and research procedures of attachment theory, particularly, the strange situation paradigm (Ainsworth, Blehar, Waters, \& Wall, 1978), opened new avenues for investigating issues that have concerned kibbutz research since the 1950 s, including the effects on infant development of early exposure to multiple caregivers in the context of group care.

According to attachment theory, the security of infants' attachment to their caregivers is determined by the quality of the care they receive (Bowlby, 1969/1982). Sensitive responses to infants' signals and needs are associated with secure attachments, whereas rejection of infants' communications and inconsistent care are related to insecure attachments (Ainsworth et al., 1978). A multiple caregiving arrangement exposes infants to repeated separations from their primary caregivers as well as to new relationships. When nonmaternal care involves group care, the feasibility of providing sensitive care to individual children within a group and the nature of relationships with additional caregivers become important issues for examination. The increasing numbers of children who are exposed to various multiple caregiving arrangements lend additional importance to the study of these issues. Therefore, our review of attachment research in kibbutzim examines the relationships of kibbutz infants and the consequences of these relationships in terms of socioemotional development.

\section{Infants' Relations With Parents}

The first studies focused on children's relations to their mothers and concluded that collective upbringing does not interfere with the intensity of attachment relations. In a stressful situation very similar to the strange situation paradigm, 2-4-yearold kibbutz children (Maccoby \& Feldman, 1972) and 8-24month-old kibbutz infants (Fox, 1977) used their mothers as a secure base. However, neither Maccoby and Feldman nor Fox were able to apply the extensive classification system of attachment behavior in the strange situation (Ainsworth et al., 1978). This is probably the reason why they chose to measure the intensity of attachment as if it were a personality trait. In current conceptualizations, attachment is viewed as a strategy of dealing with the emotions elicited by stressful events and with the status of the attachment figure in this process. Three fundamental strategies have been identified: (a) denial of negative emotions and avoidance of the attachment figure, who is not expected to provide relief (A); (b) open communication with the attachment figure about negative emotions (B); and (c) preoccupation with negative emotions and ambivalence toward the attachment figure, who for the child is both a source of stress and a potential "haven of security" (C; Main, 1990). The classification of attachment behavior in the strange situation paradigm is based on several strategies. A child's attachment to the primary caregiver can be classified as insecure-avoidant (A), secure (B), or insecure-resistant (C). The view of attachment as a relational organization underlies much of the later research.

Sagi, Lamb, Lewkowicz, et al. (1985) used the strange situation paradigm (Ainsworth et al., 1978) and its classification sys- 
tem to study the relationships of 85 communally sleeping kibbutz infants with their parents and caregivers. They also examined the relationships with their mothers of 36 Israeli infants attending city day-care facilities. They found that only $59 \%$ of kibbutz infants were securely attached to their mothers, as compared with $75 \%$ of Israeli day-care infants and the $65 \%-70 \%$ levels found in most studies. Among children with insecure attachments in both Israeli samples, anxious-ambivalent relationships were overrepresented. Skewed distributions of attachment relationships, including that found by Sagi and his colleagues, have raised concern that the strange situation may not be cross-culturally valid (Grossmann, Grossmann, Spangler, Suess, \& Unzner, 1985; Sagi, Lamb, Lewkowicz, et al., 1985). However, recent secondary analyses and meta-analyses (Sagi, Van IJzendoorn, \& Koren-Karie, 1991; Van IJzendoorn \& Kroonenberg, 1988), as well as analyses of cross-national data (Lamb, Thompson, \& Gardner, 1985; Sagi, 1990; Van IJzendoorn, 1990), have indicated that this procedure is valid for assessing universal communicative patterns between adults and infants that may be affected by stress (Van IJzendoorn \& Kroonenberg, 1988) or by cultural preferences (Sagi, 1990). Clearly, more research was needed to find precursors of attachment relationships in kibbutz children so as to understand the unusual rates of insecure relationships.

Communal sleeping in children's houses-the unique characteristic of a collective upbringing - was postulated by Sagi and his colleagues to be a possible antecedent for the development of insecure attachments, and a new study was designed to investigate this assumption. Before we describe this study, it should be noted that, until the mid-1980s, decisions about sleeping arrangements were closely related to ideological differences among the major kibbutz movements. The traditional, more politically socialist movement advocated communal sleeping and emphasized conservative interpretations of kibbutz ideology. Moreover, the transition to home-based sleeping brought further changes. The relative weight of the children's house and the influence of the metapelet were reduced in home-based sleeping, whereas the educational practices of both caregivers and parents were characterized as more permissive than in communal sleeping (Lavi, 1990b). Thus, it can be argued that sleeping arrangements were associated with a host of other important variations. However, the influence of these variations on developmental outcomes was not assessed separately from sleeping arrangements. Nathan (1984), in his summary of the relevant research, concluded that children who were raised in different sleeping arrangements were very similar on outcome variables including behavior disorders, social adjustment, self-image, and adolescents' autonomy from parents.

In a new quasi-experimental study, 23 mother-infant dyads from traditional kibbutzim (with communal sleeping arrangements) and 25 dyads from nontraditional kibbutzim (where family-based sleeping was instituted) were observed in the strange situation paradigm (Sagi, Van IJzendoorn, Aviezer, Donnell, \& Mayseless, in press). The distribution of attachment relationships for communally sleeping infants was confirmed and was even more extreme than in the earlier study: Only $48 \%$ of the infants were securely attached to their mothers. However, the distribution for infants in family-based sleeping arrange- ments was completely different. Eighty percent of these infants were securely attached to their mothers, a rate similar to that found among urban Israeli infants (Sagi, Lamb, Lewkowicz, et al., 1985).

To rule out alternative explanations for the effect of communal sleeping arrangements, assessments were also made of the ecology of the children's house during the day, maternal separation anxiety, infants' temperament, and mother-infant play interactions. The two groups (i.e., family-based and communal sleepers) were found comparable on all of these variables. Thus, it was concluded that collective sleeping, experienced by infants as a time during which mothers were largely unavailable and inaccessible, was responsible for the greater insecurity found in this group. Inconsistent responsiveness was inherent in the reality of these infants, because sensitive responding by mother or caregiver during the day sharply contrasted with the presence of an unfamiliar person at night. Inconsistent responsiveness has previously been considered to be an important antecedent condition of insecure, ambivalent attachment (Ainsworth et al., 1978).

Figure 1 represents the distribution of attachment classifications with mothers and illustrates how the collective kibbutz samples differ from other groups in Israel and elsewhere in the world. The plot is based on an earlier correspondence analysis of the then-known studies of attachment (see Van IJzendoorn \& Kroonenberg, 1988). In addition, we calculated the relative positions of the subgroups of kibbutzim both with and without collective sleeping from Sagi et al. (in press). The first dimension in Figure 1 shows a progression of an overrepresentation of the A classification on the left to an overrepresentation of the $C$ classification on the right, the second dimension indicates a $B$ versus A plus $C$ overrepresentation. The plot clearly shows that the collective kibbutz samples are very much at variance with other Israeli samples and samples from other countries. The anomalous position of the collective kibbutz samples is accounted for by the overrepresentation of insecure and, particularly, ambivalent attachments. Thus, Sagi et al.'s (in press) recent findings underscore the sensitivity of the strange situation paradigm to the nature of infants' emotional communications with their caregivers, even though they are derived from experiences in variable rearing conditions embedded in various cultural contexts.

More evidence about problematic aspects of communal sleeping can be derived from the Adult Attachment Interview (AAI; Main \& Goldwyn, 1991), which assesses adults' current mental representations with regard to their early childhood attachment relationships. Sagi et al. (1992) presented the AAI to 20 mothers from kibbutzim maintaining collective sleeping arrangements and to 25 mothers from home-sleeping kibbutzim. Parent-child concordance in attachment classifications was relatively low for the communally sleeping group (40\%) and relatively high for the home-sleeping group (76\%). Possibly, caring for infants within the ecology of collective sleeping may have disrupted the transmission of parents' internal model of relationships into their parenting style.

Sagi, Lamb, Lewkowicz, et al. (1985) also observed communally sleeping kibbutz infants with their fathers in the strange situation paradigm; they found that independent of the infants' 


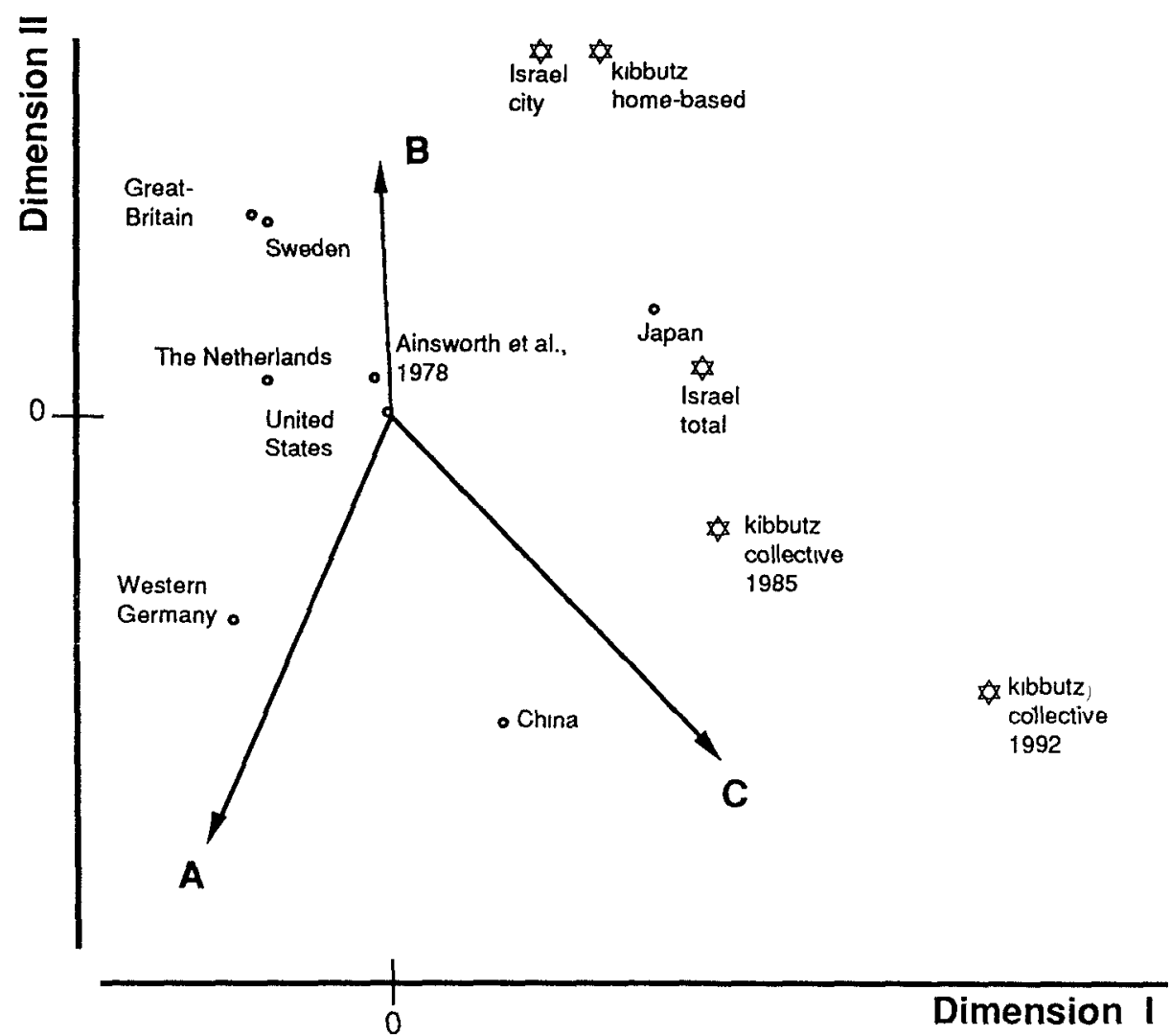

Flgure 1. Distribution of attachment classifications in various countries and in various Israeli samples (based on Van Uzzendoorn \& Kroonenberg, 1988). This plot is based on the meta-analysis by Van IJzendoorn and Kroonenberg of almost 2,000 worldwide attachment classifications. The distribution of the attachment classifications is plotted for each country by use of correspondence analysis. The origin of the plot represents the global distributions. The distance between points represents discrepancy; the direction of the discrepancy is indicated by the three vectors. Van IJzendoorn and Kroonenberg provided locations of the data points. Only Ainsworth, Blehar, Waters, and Wall's (1978) sample and the Israeli samples have individual data points in this figure. Added to Van IJzendoorn and Kroonenberg's plot is the sample of Sagi, Van IJzendoorn, Aviezer, Donnell, and Mayseless (in press). This sample is indicated by kibbutz home-based and kibbutz collective 1992. This information is also accounted for in Israel total.

attachment to mothers, the rates of secure attachments to fathers $(67 \%)$ were no lower than those commonly found in other populations. This suggests that communal sleeping has presented no particular problem for infants' relationships with their fathers. Moreover, an examination of the behavior patterns of mothers and fathers at home with communally sleeping infants aged 8-16 months revealed that kibbutz mothers and fathers behave differently toward their infants during natural interactions, in a manner similar to mothers and fathers in other cultures. However, unlike other cultures, kibbutz infants showed no preference for one parent over the other (Sagi, Lamb, Shoham, Dvir, \& Lewkowicz, 1985). The infants' lack of preference was interpreted as an indication that neither parent was functioning as the primary caregiver because kibbutz infants were being cared for in the children's house. It is possible, however, that the infants' behavior reflects their experience with parents who do not regard any part of child care as being the exclusive responsibility of only one parent (Shamai, 1992). In ad- dition, kibbutz fathers tend to spend more time with their infants than do their urban counterparts (Sagi, Koren, \& Weinberg, 1987); thus, it is possible that the time infants spend together with their parents may in itself be an important contribution to the relationships between parents and children (Clarke-Stewart, 1988).

Research on children in day care (Farran \& Ramey, 1977; Goossens \& Van IJzendoorn, 1990; Howes et al., 1992; Howes, Rodning, Galluzzo, \& Meyers, 1988), and on kibbutz children (Fox, 1977; Sagi, Lamb, Lewkowicz, et al., 1985) has suggested that caregivers and teachers function as attachment figures in addition to the parents. Sagi, Lamb, Lewcowicz, et al. (1985) observed 84 kibbutz infants with their caregivers (metaplot) in the strange situation. They classified $53 \%$ of the infant-metaplot relationships as secure, independently of the classifications of these infants' relationships with their mothers and fathers. Goossens and Van IJzendoorn (1990), in a Dutch sample, and Howes et al. (1992), in an American sample, found similar 
rates of secure relationships between children and their caregivers (57\% and $51 \%$, respectively). Although these rates of security were somewhat lower than those commonly found between infants and parents, Sagi and Van IJzendoorn (in press) and Van IJzendoorn, Sagi, and Lambermon (1992) concluded, from an evaluation of two data sets (Goossens \& Van IJzendoorn, 1990; Oppenheim, Sagi, \& Lamb, 1988), that it is justified to argue that infants indeed develop attachment relationships to their professional caregivers and that these relationships reflect the interactive history of the caregiver-infant dyad. Note that the rates of secure relationships with mothers found in kibbutzim where communal sleeping is in force (59\%) actually resemble rates found for secure relationships with caregivers $(51 \%-57 \%)$. One can conclude that in an environment of multiple caregivers, children form multiple attachment relationships that are independent of each other.

Note that the traditional argument favored by attachment theory (Main \& Weston, 1981; Sroufe, 1985) about the lack of concordance in the attachment relationships of a single infant to its mother and father has been recently challenged by Fox, Kimmerly, and Schafer (1991). Their meta-analytic study on the concordance of infant-mother and infant-father attachment showed a significant-albeit small-degree of similarity between these two relationships. One might speculate that the concordance of attachment between parental and nonparental caregivers is weak or absent because assortative mating is much less likely to play a role. Steele, Steele, and Fonagy (1993) proposed that the concordance between infant-mother and infantfather attachment quality exists because of the concordance between maternal and paternal attachment representations. In a combination of studies on the concordance of attachment representations in husbands and wives, Van $1 \mathrm{Jzendoorn}$ and Bakermans-Kranenburg (in press) found a modest association: Secure wives are more often married to secure husbands than might be expected by chance. If attachment is transmitted across generations, this association would lead to a correspondence between infant attachment to father and infant attachment to mother. Although pertinent data are lacking, the same association seems unlikely between parental and nonparental attachment representations. In the same vein, maternal modeling of caregiving behaviors that might determine the quality of infant attachment is more likely between a child's mother and father than between the child's parents and nonparental caregivers. In an environment of multiple caregivers, therefore, attachment relationships might be independent, at least for parental and nonparental caregivers. More data on attachment networks and attachment representations in the kibbutz are needed to confirm these speculations.

\section{Consequences of Attachment Relationships}

These recent findings of attachment research in a sense support Rabin's (1965) argument that kibbutz infants suffer from a partial psychological deprivation; they also suggest that collective sleeping is an important contributing factor to this effect. Such a conclusion would be in accord with the findings of earlier research that collective sleeping has a long-lasting moderating impact on socioemotional needs and styles (Berman, 1988; Re- gev et al., 1980). Rabin conjectured that partial deprivation of this kind in infancy has a very limited long-term effect on development. Additional data must be examined to assess whether the quality of early relationships, as assessed in the strange situation paradigm, has a long-term developmental effect.

Oppenheim et al. (1988) assessed a broad spectrum of socioemotional competencies of most of the subjects in the sample of Sagi, Lamb, Lewkowicz, et al. (1985) when they were 5 years old in an attempt to understand the consequences of early relationships. They found that secure attachment to the caregiver during infancy was the strongest predictor of children being empathic, dominant, independent, achievement oriented, and behaviorally purposive in kindergarten; on the other hand, no significant relationships were found between these socioemotional developments and the quality of children's attachment to their parents. These results suggest that the influence of attachment relationships may be viewed as domain specific. Because the infants' relations with caregivers had been formed in the context of the infant house, they are the best predictor of children's socioemotional behavior in similar contexts.

However, one can expect attachment relationships in a multiple caregiver environment to interact in such a way that the predictive power of individual relationships is weaker than that of their combination (Howes et al., 1988; Tavecchio \& Van IJzendoorn, 1987). Van IJzendoorn, Sagi, and Lambermon (1992) examined a sample of kibbutz children and a sample of Dutch children for the predictive power of the extended network of infants' relationships (mother, father, and professional caregiver) in comparison with the family network (mother and father) and the mother-infant relationship. They found that secure extended-network relationships were the best predictor of later advanced socioemotional functioning, although this finding was much stronger for kibbutz children. In the Dutch sample, the security of the extended network was related to children's higher developmental quotient and autonomous behavior in preschool. However, in the kibbutz sample, security of the extended network was related to a higher IQ and more independent behavior in kindergarten, as well as to higher ego resilience, ego control, field independence, dominance, goal-directed behavior, and empathy. Security of the family network in the kibbutz was also related to some of these variables, whereas infantmother relationships were, by themselves, unrelated to any of the children's outcome variables. Thus, one can conclude that the quality of early relationships does predict future development. However, the ecology of infant care in regard to the extent of the child's exposure to multiple relationships determines the relative contribution of individual relationships to developmental outcome.

Moreover, there is evidence here, as well as in Howes et al. (1988), that within a matrix of multiple relationships, secure relationships with professional caregivers are not only feasible but also contribute to the child's well-being by either adding to a network of secure attachments or, possibly, compensating for their absence. Relationships between professional caregivers and children thus have the potential of adding a significant dimension to children's socioemotional development without interfering with the parent-child relationship, as was strongly believed by kibbutz educators (Gerson, 1978). 


\section{Summary and Discussion}

The study of kibbutz child rearing from the perspective of attachment theory has allowed a direct assessment of the impact of multiple caregiving in infancy both on children's experience as infants and on their future development. Investigations of collective child rearing, with its unique philosophy and practices, highlight issues that may be pertinent to other multiplecare arrangements but tend to be overlooked or underrated. On the basis of data available from studies of kibbutz children, one can conclude that early extensive day care and the repeated separation from parents inherent to such care do not necessarily interfere with the formation of close relationships between parents and children. The similarly high rates of secure attachments found in kibbutzim practicing family-based sleeping and in Israeli day care centers, and their difference from both samples of communal sleeping (see Figure 1), suggest that neither day care nor kibbutz care can in itself explain the unusual rates of insecure attachments found in kibbutzim with collective sleeping arrangements. Rather, the increase in infants' insecurity probably reflects a child-care environment in which infants experience inconsistent care as a result of parental absence during the night without an adequate replacement.

Nevertheless, understanding the effects of collective sleeping, which is an extreme practice, may highlight the effects of the repeated separations from mothers that are inherent in any multiple caregiving arrangements. Two variables have been proposed to attenuate the effects of separations on the quality of infant attachment: high-quality alternative caregiving (Goossens, 1987; Howes et al., 1988), which may alleviate the stress that infants experience in situations of maternal absence, and maternal compensating efforts, which may moderate the effects of temporary traumatic separations (e.g., those occurring as a result of hospitalizations) so as not to result in long-term insecurity (Van IJzendoorn, Goldberg, Kroonenberg, \& Frenkel, 1992). Collective sleeping arrangements have been problematic in both respects. Although kibbutzim have provided high-quality child care during the day, the quality of night care in the infant house has been poor because it has most often been provided by strangers who can offer only a precarious sense of security to the infants. On the other hand, maternal compensation is not very likely, because even sensitive parents may not feel an urgency to compensate for their absence during the night in a situation in which routinely implemented separations are the norm for all of the children in the community. This circumstance points to the dangers inherent in maintaining multiple care arrangements for infants without also guaranteeing alternative caregiving of adequate quality.

A number of studies have shown that quality caregiving (Droege \& Howes, 1991; Howes et al., 1992; Rosenthal, 1991) is relevant to children's socioemotional development in that it determines the quality of children's experience in day care and affects parent-child relations (Goossens, 1987; Howes et al., 1988). In this regard, therefore, one should consider the discrepancy between the quality of collective child care during the day and during the night. More specifically, the low-quality aspect of kibbutz child care, which is associated with collective sleeping, must be controlled for when dealing with the broader contro- versy about the impact of extensive day-care experience in infancy on socioemotional development (Belsky, 1988; ClarkeStewart, 1988, 1989; Gamble \& Zigler, 1986). Indeed, the finding of normal rates of secure attachment among kibbutz infants, who experience early and extensive care of high quality during the day and who sleep at home at night, is consistent with studies that suggest that high quality of care is an important determinant of children's socioemotional experience (e.g., Howes, 1990; Howes et al., 1992).

We have until now emphasized the increased rates of insecure attachment in situations of collective sleeping. However, one should not overlook the fact that almost $50 \%$ of the mothers of communally sleeping infants have been able to provide their infants with a sense of a consistent, secure relationship. This group underscores the need to understand resiliency in the face of adverse conditions (Belsky, 1990).

The finding that both the extended network and the family network in kibbutzim have more predictive power than does the mother-child relationship may be explained by the greater involvement of kibbutz fathers and caregivers in child care. Recall that the increased involvement of others in child care was regarded as beneficial to both women and children and had an important ideological value. In Israel, kibbutz fathers tend to spend more time with their infants than do nonkibbutz fathers (Sagi et al., 1987), possibly because the organization of kibbutz life allows both parents equal time to spend with their children. More time for leisure and availability of Israeli fathers have been found to determine the extent of their play and affiliative behaviors, whereas their attitudes and perceptions regarding fatherhood have predicted caregiving and play (Levy-Shiff \& Israelashvili, 1988).

As a result of the high value placed by kibbutz culture on parental involvement (Shamai, 1992), no aspects of child care have been viewed by parents of either sex as being the exclusive responsibility of one parent or the other. Yet, the duties of professional caregiving have never been assumed by kibbutz men. Thus, it would seem that kibbutz fathers are relatively privileged because they have more leisure time with their children within a culture that values paternal involvement in child care but does not regard the father as having primary responsibility. However, in the name of women's equality, which used masculine criteria for achievements (Palgi, Blasi, Rosner, \& Safir, 1983), maternal involvement in child care has been reduced. It would appear, then, that in comparison with other child-rearing environments, collective education has supported father-child relationships while being ambiguous toward mother-child relationships. This may explain the differential influence exerted by collective education combined with communal sleeping on infants' relationships with their mothers and fathers and the similarity in rates of security between mothers and caregivers (Sagi, Lamb, Lewkowicz, et al., 1985). Recently published autobiographical recollections of kibbutz-raised women (Leshem, 1991) support this conclusion.

The kibbutz data suggest that as women increase their involvement in out-of-home employment and increasingly share the duties of caring for their children with other caregivers (professionals or family members), the relative influence of the mother-child relationship may also change. Role changes 
within families, as they translate into daily functioning, may affect parental relationships with infants, and different childrearing conditions may increase or decrease the influence of these relationships on children's development (Belsky, 1990). Given the processes of change experienced by many families, there is a need for more information about the attitudes of parents toward child care and parenting roles; such information will provide a better understanding of the interrelationships among child-care ecology, parental functioning, and children's relations with parents. The consequences of these changes for children's development in different ecologies and cultures remain an empirically open question. We have thus far focused on children's relations with various adults, but the collective orientation of the kibbutz has also been manifested in the role assigned to the peer group in the socialization of children. Therefore, our review would be incomplete without a discussion of the relations of kibbutz children with their peers.

\section{Relations With Peers}

In the educational conceptualization of collective education, the peer group was viewed as offering a natural environment for children's activity because it both directs their behavior and protects their independence (Golan, 1961). Group activities and sharing, as well as respect for the rights of others, were emphasized by adults from an early age (Rabin \& Beit-Hallahmi, 1982). At the time, this view was at odds with the prevailing belief that young children were unable to benefit from group life because of their competition for the attention and love of adults (Freud, 1973; Isaacs, 1948) and their egocentric and noncommunicative thinking (Piaget, 1959). Group living among children from the time of infancy, as practiced in kibbutzim, has intrigued some observers who have been impressed by the unexpected presence of emotional ties between infants and toddlers. Bettelheim (1969) and Kaffman (1965) described close relations between such infants and detected distress when one of the infants was absent. Zaslow (1980) found that individual group members were sought out as early as the end of the 1st year, and such closeness was influenced by sharing a room in the infants' house, mutual responsiveness, and close relations between parents. Spiro (1958) observed 10-month-old infants playing together so often that they seemed to be a subgroup within the large group and described the peer group as a constant source of stimulation as well as security. Winograd (1958) observed mutuality and empathy in the behavior of children much younger than the age at which such behaviors were assumed to be meaningful.

Recent research on infants and toddlers together (Eckerman \& Didow, 1988) suggests that the observations just reported have captured a natural social capacity readily displayed by kibbutz children because of the intensive social character of their environment. Although infant sociability is viewed as a natural capacity, it must be distinguished from social competence, which refers to effectiveness with peers through coordinated interactions and reciprocal actions within a relevant affective context. Early peer encounters have been thought to provide children with the social experience necessary to support the development of social competence (Eckerman \& Didow, 1988;
Howes, 1988a). Moreover, it has been suggested that peer familiarity facilitates social interaction and the development of specific relationships based on the continued presence of the partner (Doyle, Connolly, \& Rivest, 1980; Howes, 1988a). Kibbutz infants and toddlers are exposed to peers very early, the peer group is stable, and peer familiarity is very high. In addition, adults value the role of peers in children's lives. These features of peer experience have been found to facilitate social competence in young children (Howes, 1988a); thus, one can expect social competence to be well developed among kibbutz children.

Two kinds of studies have assessed social competence in kibbutz infants, toddlers, and preschoolers: investigations of group processes and peer relationship formation and assessments of play quality as a demonstration of social skills. The data indicate that kibbutz children are competent in both respects. Faigin (1958) found that 2-year-old toddlers had already developed a strong identity with the group, expressed in concepts such as "we" and "ours" and by mutual defense of group members in between-groups competitions and rivalries. Although leadership belongs to the metapelet, the group functions as a socializing agent in terms of controlling the behavior of its members. Laikin, Laikin, and Constanzo (1979), as well as Y. Harel (1979), explored group processes in toddler groups and identified group behaviors at very young ages; however, role taking, following group "rules," and negotiations in regard to objects and toys were found to be behaviors that develop with age. Play in groups formed according to children's choice, which increased in frequency between the ages of 24 and 30 months, involved more mature and intensive social interactions than parallel play or whole-group activities not involving choice ( $Y$. Harel, 1979).

Ross, Conant, Cheyne, and Alevizos (1992) recently published a study that investigated toddlers' relationships and conflict interventions in two kibbutz groups whose members' average age was 20 months. They found that unique adjustments were made by children in their interactions with specific partners and observed conflicts as well as positive interactions. These adjustments tended to be mutual and spanned broad periods of time, thus taking the form of reciprocal relationships in which conflicts and positive interactions were integrated. Considerations of rights and fairness seemed to guide thirdparty conflict interventions, which sometimes involved attempts to mediate, compensate, or reprimand; however, alliances more than fairness determined the outcome of a conflict. These behaviors were taken as an indication that very young children are able to sort out the nature of social exchanges in which they were not initially involved. The nature of peer relations in these groups, with their siblinglike familiarity that afforded members a comfortable context for acquiring social experience, may have made such sophisticated behaviors possible.

Studies that have evaluated play quality and social behavior among kibbutz and urban Israeli children reveal that kibbutz children are very skilled social players. Toddlers from kibbutzim were found to be more likely to engage in positive social interaction with peers than family day-care and center day-care children (Rosenthal, 1991). Kibbutz toddlers were more in- 
volved in associative-dramatic play and showed less unoccupied behavior and parallel play. Functional play appeared earlier in kibbutz nursery school children, but it was more frequently observed among urban kindergarten children (Meerovitch, 1990). Finally, kibbutz children displayed coordinated play more frequently and were less competitive in group encounters and less involved in object exchange and struggle over toys; however, they were also less affectively involved with their peers and more verbally aggressive than were urban nursery school children. When kibbutz children were not interacting with peers, they spent more time in solitary play and interaction with the caregivers and less time watching their peers (LevyShiff \& Hoffman, 1985). However, communally sleeping preschoolers exhibited lower levels of effective problem solving but higher autonomy in daily routine tasks, despite parents' reports that did not indicate that kibbutz children were less attached to them (Levy-Shiff, 1983).

The data suggest that although social competence is developmental, the social environment that provides the context for its acquisition has a strong impact. The attitudes of adults toward early peer interaction influence the social environment of children and thus may play an important role in children's social experience (Howes, 1988a). Indeed, kibbutz caregivers emphasize group behaviors at a very early stage (Faigin, 1958; Rabin \& Beit-Hallahmi, 1982). In interviews, caregivers have reported that they encourage children to help one another and to share (Laikin et al., 1979), as well as to engage in social rather than individualistic achievements (Meerovitch, 1990). In addition, adult actions and attitudes have been observed to have an impact on children's behaviors. Y. Harel (1979) reported that children used initiations and rule-setting behaviors to which they had previously been introduced by their caregivers, and Zaslow (1980) identified close relationships between parents as a variable related to closeness between infants. Richman's (1990) findings supported the hypothesis that kibbutz children will behave more prosocially than nonkibbutz children because prosocial behavior reflects children's experience with expectations in their environment. Moreover, he found that kibbutz kindergarten children whose parents and caregivers were themselves kibbutz born helped more and that kibbutz children whose metaplot were kibbutz born shared more. Richman thus concluded that the expectations of kibbutz-born adults concerning prosocial behavior have had an impact on the children they bring up.

The research reported thus far suggests that peers are emotionally important to kibbutz infants and toddlers and that prosocial behaviors are found at a very early age among kibbutz children. However, social behaviors are developmental, and adults play an important part in the learning of such behaviors. It seems reasonable to assume that the influence of the peer group derives from its stable presence and from the continuity of interpersonal relationships that it allows, as well as from adult emphasis on the importance of the group and of group rules and values. The pervasiveness of the early peer group may also be illustrated with studies that have shown that early peers do not tend to marry each other in adulthood because they seem to consider themselves more like siblings (Shepher, 1971).

However, a complex picture regarding the development of so- cial competence emerges from this review. It seems that young kibbutz children display advanced group-oriented skills and sophisticated behaviors in peer interactions together with indications of greater affective distancing and lower levels of affective problem-solving skills. Affective behavior and problem-solving skills-neither of which are group-oriented skills-are involved in social competence and have been predicted on the basis of the quality of attachment relationships (Sroufe \& Fleeson, 1986), which also determine children's social competence in interactions with peers (Easterbrooks \& Lamb, 1979; Sroufe \& Fleeson, 1986). Within this framework of attachment theory, both lower problem skills and lower capacity for intimacy can be related to the higher rates of insecurity found among communally sleeping infants (Sagi, Lamb, Lewkowicz, et al., 1985; Sagi et al., in press), thereby explaining the coexistence of high sociability and low intimacy.

Thus, the intensive social nature of the environment of kibbutz children could support their acquisition of advanced social skills, whereas the complicated socioemotional nature of their experience in communal sleeping underlies their affective behaviors and style. This theoretical basis allows one to predict that home-based kibbutz toddlers will be more competent than their collectively sleeping counterparts. Indeed, Laikin et al. (1979) found more mature social interaction in groups of homebased sleeping toddlers than in communally sleeping groups, which they explained in terms of different interactive needs. Alternatively, the higher competence of home-based toddlers may be attributed to the more extensive nature of their interpersonal experience in their families. Unfortunately, these conclusions are only tentative because no research, to the best of our knowledge, has directly explored the association between family interactions and social competence among kibbutz children from the two ecologies. Moreover, because the studies of social competence in kibbutz children represent a variety of theoretical formulations, operational definitions, and measurements, it is difficult to derive a single conclusive interpretation. The various facets of social development in very young children who experience an intensive social environment, as increasing numbers of children do, and the specific conditions that shape social development are topics for further research, which may be especially interesting to pursue with kibbutz children.

\section{Summary and Conclusions}

Collective child-rearing represents a special case of group care because children's exposure to multiple significant others and to peer-group living, although serving adults' goals, was put into practice as a result of the belief of adults that it was beneficial to children. The present review shows that collective kibbutz education has undergone tremendous changes in the course of the 70 years of its existence. Initially, an extreme form of collectivism, motivated by economic needs and ideological convictions, was instituted. Its intended goal was to nourish a "new type" of human being that would be untainted by the shortcomings that those who instituted the practice had observed in their own upbringing.

Judged strictly in terms of this ambition alone, collective education can be regarded as a failure. The family as the basic 
social unit has not been abolished in kibbutzim. On the contrary, familistic trends have become stronger than ever, and kibbutz parents have reclaimed their rights to care for their own children. Collective education has not produced a new type of human being, and any differences found between adults raised on and off the kibbutz have been minimal. Moreover, research results indicate that collective sleeping arrangements for children negatively affect socioemotional development in the direction of a more anxious and restrained personality. Collective sleeping, which may have been justified in early periods in the history of kibbutzim, was abolished as it became clear that it did not serve the emotional needs of most kibbutz members. Its disappearance demonstrates the limits of adaptability of parents and children to inappropriate child-care arrangements.

However, setting aside communal sleeping as too radical a practice, collective child rearing seen from a broader perspective has to its credit remarkable achievements unprecedented in other cultures. It has furnished high-quality care for all of the children in the community without exception and long before multiple caregiving was contemplated for the population at large. Only in Eastern Europe have such attempts been made, at the cost of providing mediocre care (Weigl \& Weber, 1991). Collective education has developed a long-term practice of normal multiple caregiving that is supported by caregivers and parents, as well as the community. Thus, with the discontinuance of collective sleeping, secure relationships have come to prevail to an extent similar to that found among nonkibbutz children. Collective education affords children the benefit of a network of relationships in a supportive environment.

The kibbutz practice of raising children in peer groups from infancy highlights the role of peers in children's social experiences and the contribution of these experiences to the development of social competence. However, social competence is a multifaceted construct that includes group-oriented skills as well as intimacy, affective behavior, and emotional style. Grouporiented skills can be facilitated by a social environment of familiar peers in which group behaviors are supported by adults' guidance. The affective dimension seems to require secure relationships with sensitive and responsive adults; these relationships may provide the foundation for the capacity to enter intimate relations with others. Further research is needed to understand the complexities of children's social competence.

The kibbutz, as a unique experiment in nature (Beit-Hallahmi \& Rabin, 1977), has contributed to theories of early socioemotional development while reiterating the detrimental effects of poor-quality care in institutional settings (Bowlby, 1951; Spitz, 1946). Nevertheless, leaving aside the practice of communal sleeping arrangements, the kibbutz child-care system demonstrates the potentials of sharing tasks and responsibilities of child rearing with nonparental caregivers-without detrimental effects for either the children or the parents involved-and underscores some of the conditions that have to be taken into account in the current day-care debate regarding the influence of extensive day-care experiences during infancy on later socioemotional development.

\section{References}

Ainsworth, M. D. S., Blehar, M., Waters, E., \& Wall, S. (1978). Patterns of attachment. Hillsdale, $\mathrm{NJ}$ : Erlbaum.
Alon, M. (1976). Mishnato hachinuchit shel Shmuel Golan [The educational thought of Shmuel Golan]. In Y. Arnon (Ed.), Hachinuch hameshutaf(pp. 11-24). Tel Aviv, Israel: Sifriyat Poalim.

Anthony, E. J., \& Bene, E. (1957). A technique from the objective assessment of the child's family relationships. Journal of Mental Science, 103, 541-555.

Barry, H., \& Paxton, L. M. (1971). Infancy and early childhood: Crosscultural codes 2. Ethnology, 10, 466-508.

Bar-Yosef, R. (1959). The pattern of early socialization in the collective settlements of Israel. Human Relations, 12, 345-360.

Beck, S. J. (1950). Rorschach's test (Vol. 1). New York: Grune \& Stratton.

Beit-Hallahmi, B. (1981). The kibbutz family revival or survival. Journal of Family Issues, 2, 259-274.

Beit-Hallahmi, B., \& Rabin, A. (1977). The kibbutz as a social experiment and as a child-rearing laboratory. American Psychologist, 12 57-69.

Belsky, J. (1988). The effects of infant day-care reconsidered. Early Childhood Research Quarterly, 3, 235-272.

Belsky, J. (1990). Parental and nonparental child care and children's socioemotional development: A decade in review. Journal of Marrlage and the Family, 52, 885-903

Ben-Yaakov, Y. (1972). Methods of kibbutz collective education during early childhood. In J. Marcus (Ed.), Growing up in groups (pp. 197295). London: Gordon \& Beach.

Berman, E. (1988). Communal upbringing in the kibbutz. Psychoanalyttc Study of the Child, 43, 319-335.

Bettelheim, B. (1969). The children of the dream. London: Collier-Macmillan.

Bowlby, J. (1951). Maternal care and mental health Geneva: World Health Organization.

Bowlby, J. (1982). Attachment and loss Vol 1. Attachment New York: Basic Books. (Original work published 1969)

Bronson, G. W. (1968). The development of fear in man and other animals. Child Development, 39, 409-432.

Clarke-Stewart, K. A. (1988). "The effects of infant day-care reconsidered" reconsidered: Risks for parents, children, and researchers. Early Chlldhood Research Quarterly, 3, 292-318.

Clarke-Stewart, K. A. (1989). Infant day care: Maligned or malignant? American Psychologist, 44, 266-273.

Doyle, A., Connolly, J., \& Rivest, L. (1980). The effect of playmate familiarity on the social interaction of young children. Child Development, 51, 217-223.

Droege, K. L., \& Howes, C. (1991, July). The influence of caregiver behavior on children's affective displays Paper presented at the biennial meeting of the International Society for the Study of Behavioral Development, Minneapolis, $\mathrm{MN}$

Easterbrooks, M. A., \& Lamb, M. (1979). The relationship between quality of infant-mother attachment and infant competence in initial encounters with peers. Child Development, 50, 380-387.

Eckerman, C. O., \& Didow, S. M. (1988). Lessons drawn from observing young peers together. Acta Padiatrica Scandinavica, 77(Suppl. 344), $55-70$.

Epstein, R. (1992, March). Sheina baklbbutz-Lina meshutefet mul lina mishpachtit [Sleep in the kibbutz-collective versus home-base sleeping]. Paper presented at the Technion Workshop on Studies of Sleep in Children, Haifa, Israel.

Faigin, H. (1958). Social behavior of young children in the kibbutz. Journal of Abnormal and Social Psychology, 56, 117-129.

Farran, D. C., \& Ramey, C. T. (1977). Infant day care and attachment behaviors toward mothers and teachers. Child Development, 48, 1112-1116. 
Fein, G. G., \& Fox, N. (1988). Infant day care: A special issue. Early Childhood Research Quarterly, 3, 227-234.

Feldman, S. S., \& Yirmiya, N. (1986). Perception of socialization roles: A study of Israeli mothers in town and kibbutz. International Journal of Psychology, 21, 153-165.

Fölling-Albers, M. (1988a, July). Education in the kibbutz as "women's business": Emancipation of women between idea and reality. Paper presented at Utopian Thought and Communal Experience, New Lanark, Scotland.

Fölling-Albers, M. (1988b). Erziehung und frauenfrage im kibbutz [Child rearing and women's emancipation in the kibbutz]. In W. Melzer \& G. Neubauer (Eds.) Der kibbutz als utopie (pp. 88-120). Basel, Switzerland: Beltz.

Fox, N. (1977). Attachment of kibbutz infants to mother and metapelet. Child Development, 48, 1228-1239.

Fox, N., Kimmerly, N. L., \& Schafer, W. D. (1991). Attachment to mother/attachment to father: A meta-analysis. Child Development, 62, 210-225.

Freud, A. (1973). Normality and pathology in childhood. London: Hogarth Press.

Gamble, T. J., \& Zigler, E. (1986). Effects of infant daycare: Another look at the evidence. American Journal of Orthopsychiatry, 56, 2642.

Gerson, M. (1976). Hitnahaguta hachinuchit shel metapelet bapeuton [The educational behavior of a caregiver in the toddlers' house]. In Y. Arnon (Ed.), Hachinuch hameshutaf (pp. 123-144). Tel Aviv, Israel: Sifriyat Hapoalim.

Gerson, M. (1978). Family, women, and socialization in the kibbutz. Lexington, MA: Heath.

Gerson, M., \& Nathan, M. (1969). Seker hametaplot bagil harach batnua hakibutzit [A survey of caregivers in early education in the kibbutz movement]. Yediot (3). Oranim, Israel: Institute for Research on Collective Education.

Gerson, M., \& Schnabel-Brandes, A. (1990). The educational approach of the metapelet of young children in the kibbutz. In Z. Lavi (Ed.), Kibbutz members study kibbutz children (pp. 40-49). New York: Greenwood Press.

Gewirtz, J. (1965). The course of infant smiling in four child-rearing environments in Israel. In B. M. Foss (Ed.), Determinants of infant behavıor III (pp. 205-260). New York: Wiley.

Golan, S. (1958). Collective education in the kibbutz. American Journal of Orthopsychiatry, 28, 549-556.

Golan, S. (1959). Collective education in the kibbutz. Psychiatry, 22, $167-177$

Golan, S. (1961). Hachinuch hameshutaf [Collective education]. Tel Aviv, Israel: Sifriat Poalim.

Goossens, F. A. (1987). Maternal employment and day care: Effects on attachment. In L. W. C. Tavecchio \& M. H. van IJzandoorn (Eds.), Attachment in social networks (pp. 135-183). Amsterdam: Elsevier.

Goossens, F. A., \& Van IJzendoorn, M. H. (1990). Quality of infants' attachment to professional caregivers: Relations to infant-parent attachment and day-care characteristics. Child Development, 61, 832837.

Greenbaum, C. W., \& Landau, R. (1977). Mothers' speech and the early development of vocal behavior: Findings from a cross-cultural observation study in Israel. In P. H. Leiderman, S. R. Tulkin, \& A. Rosenfeld (Eds.), Culture and infancy: Variations in the human experience (pp. 245-270). San Diego, CA: Academic Press.

Grossmann, K., Grossmann, K. E., Spangler, G., Suess, G., \& Unzner, L. (1985). Maternal sensitivity and newborns' orientation responses as related to quality of attachment in northern Germany. Monographs of the Society for Research in Child Development, 50(1-2, Serial No. 209).
Haas, M. (1986). Peutim poalim umitnasim beargaz hagrutaot ubeteivot peilut [Toddlers acting and experiencing the junk and activity boxes]. Oranim, Israel: Institute for the Teaching of Science and the Improvement of Teaching Methods.

Harel, M. (1986, September). Dialogues at risk. Paper presented at the International Conference for Infant Mental Health, Chicago.

Harel, Y. (1979). Hitnahagut chevratit bikvutsat peutot bakibbutz [Social behavior in toddlers' groups in the kibbutz]. Unpublished master's thesis, University of Haifa, Haifa, Israel.

Hazan, B. (1973). Introduction. In A. I. Rabin \& B. Hazan (Eds.), Collective education in the kibbutz (pp. 1-10). New York: Springer.

Holdstein, I., \& Borus, J. F. (1976). Kibbutz and city children: A comparative study of syntactic and articulatory abilities. Journal of Speech and Hearing Disorders, 4, 10-15.

Howes, C. (1988a). Peer interaction of young children. Monographs of the Society for Research in Child Development, 53(1, Serial No. 217).

Howes, C. (1988b). Relations between early child care and schooling. Developmental Psychology, 24, 53-57.

Howes, C. (1990). Can age of entry into child care and the quality of child care predict adjustment in kindergarten? Developmental Psychology, 26, 292-303.

Howes, C., Phillips, D. A., \& Whitebook, M. (1992). Thresholds of quality: Implications for the social development of children in centerbased child care. Child Development, 63, 449-460.

Howes, C., Rodning, C., Galluzzo, D. C., \& Meyers, L. (1988). Attachment and child care: Relationships with mother and caregiver. Early Childhood Research Quarterly, 3, 403-416.

Irvine, E. E. (1952). Observations on the aims and methods of child rearing in communal settlements in Israel. Human Relations, 5, 247 275.

Isaacs, S. (1948). Social development in young children. London: Kegan Paul, Trench, \& Trubner.

Kaffman, M. (1965). A comparison of psychopathology: Israeli children from kibbutz and from urban surroundings. American Journal of Orthopsychiatry, 35, 509-520.

Kaffman, M., Elizur, E., \& Rabinowitz, M. (1990). Early childhood in the kibbutz: The 1980s. In Z. Lavi (Ed.), Kibbutz members study kibbutz children (pp. 17-33). New York: Greenwood Press.

Keller, S. (1983). The family in the kibbutz: What lessons for us? In M. Palgi, J. R. Blasi, M. Rosner, \& M. Safir (Eds.), Sexual equality: The Israeli kibbutz tests the theories (pp. 227-251). Norwood, PA: Norwood.

Kohen-Raz, R. (1968). Mental and motor development of kibbutz, institutionalized and home-reared infants in Israel. Child Development, 39, 489-504.

Konner, M. (1977). Infancy among the Kalahari desert San. In P. H. Leiderman, S. R. Tulkin, \& A. H. Rosenfeld (Eds.), Culture and infancy (pp. 287-328). San Diego, CA: Academic Press.

Laikin, N. G., Laikin, M., \& Constanzo, P. R. (1979). Group processes in early childhood: A dimension of human development. International Journal of Behavioral Development, 2, 171-183.

Lamb, M. E., Sternberg, K. J., Hwang, C. P., \& Broberg, A. G. (Eds.). (1992). Child care in context: Cross cultural perspectives. Hillsdale, NJ: Erlbaum.

Lamb, M. E., Thompson, R. A., \& Gardner, W. (1985). Measuring individual differences in strange situation behavior. In M. E. Lamb, R. A. Thompson, W. Gardner, \& E. L. Charnov (Eds.), Infant-mother attachment (pp. 203-222). Hillsdale, NJ: Erlbaum.

Lavi, Z. (1984, April). Correlates of sleeping arrangements of infants in kibbutzim. Paper presented at the International Conference for Infant Studies, New York.

Lavi, Z. (1990a). Introduction. In Z. Lavi (Ed.), Kibbutz members study kibbutz children (pp. 1-16). New York: Greenwood Press. 
Lavi, Z. (1990b). Transition from communal to family sleeping arrangement of children in kibbutzim: Causes and outcome. In Z. Lavi(Ed.), Kibbutz members study kibbutz children (pp. 51-55). New York: Greenwood Press.

Leshem, N. (1991). Shirat hadeshe [The song of the grass: Conversations with women of the kibbutz first generation]. Ramat Efal, Israel: Yad Tabenkin.

Levy-Shiff, R. (1983), Adaptation and competence in early childhood: Communally raised kibbutz children versus family raised children in the city. Child Development, 54, 1606-1614.

Levy-Shiff, R., \& Hoffman, M. A. (1985). Social behavior of urban and kibbutz preschool children in Israel. Developmental Psychology, 21, 1204-1205.

Levy-Shiff, R., \& Israelashvili, R. (1988). Antecedents of fathering: Some further exploration. Developmental Psychology, 24, 434-440.

Lewin, G. (1982). Megamot bachinuch bagil harach [Trends in early education]. Hachinuch Hameshutaf, 105, 29-35.

Lewin, G. (1983). Kvutsat hapeutim vehametapelot-Ma kore lema'ase? [The toddlers' group and the caregivers-What happens in practice?]. Hachinuch Hameshutaf, 108, 4-24.

Lewin, G. (1985). Tahalichei shinui bachinuch hameshutaf bagil harach [Processes of change in early care in collective education]. Oranim, Israel: Institute for the Teaching of Science and the Improvement of Teaching Methods.

Lewin, G. (1986). Hachinuch hameshutaf leor hazichronot [Collective education as reflected in memories]. Hachinuch Hameshutaf, 122, 4-83.

Lewin, G. (1990). Motherhood in the kibbutz. In Z. Lavi (Ed.), Kibbutz members study kibbutz children (pp. 34-39). New York: Greenwood Press.

Liegle, L. (1974). Gezin en gemeenschap in de kibboetz [Family and community in the kibbutz]. Utrecht, The Netherlands: Spectrum.

Maccoby, E., \& Feldman, S. (1972). Mother attachment and stranger reactions in the third year of life. Monographs of the Society for Research in Child Development, 37(1, Serial No. 146).

Machover, K. (1949). Personality projection in the drawing of the human figure. Springfield, IL: Charles C Thomas.

Main, M. (1990). Cross-cultural studies of attachment organization: Recent studies, changing methodologies, and the concept of conditional strategies. Human Development, 33, 48-61.

Main, M., \& Goldwyn, R. (1991). Adult attachment rating and classification systems. Unpublished manuscript, University of California, Berkeley.

Main, M., \& Weston, D. R. (1981). The quality of toddler's relationship to mother and to father: Related to conflict behavior and the readiness to establish new relationships. Child Development, 52, 932-940.

Meerovitch, A. (1990). Hitpatchut hamischak bagil harach bair ubakibbutz-Hashpa'at hasviva al hitpatchut hahebetim hakognitivi vehachevrati shel hamischak bagil harach [Early childhood play development in the kibbutz and in the city-Influence of the environment on development of the cognitive and social aspects of play in early childhood]. Unpublished master's thesis, Bar Ilan University, Ramat Gan, Israel.

Melhuish, E. C., \& Moss, P. (1991). Day care for young children: International perspectives. London: Tavistock.

Melzer, W. (1988). Die bedeutung von utopien fur die genese der kibbutzim und ihres erziehungsarrangements [The importance of utopias for the creation of kibbutzim and their educational practices]. In W. Melzer \& G. Neubauer (Eds.), Der kibbutz als utopie (pp. 38-69). Basel, Switzerland: Beltz.

Melzer, W., \& Neubauer, G. (1988). Was ist ein kibbutz? Theoretischer anspruch und wirklichkeit-erfahren in kibbutz Ayeleth Hashahar [What is a kibbutz? Theory and practice in kibbutz Ayeleth-Hasha- har]. In W. Melzer \& G. Neubauer (Eds.), Der kibbutz als utopie (pp. 24-37). Basel, Switzerland: Beltz.

Morelli, G. A., \& Tronick, E. Z. (1991). Efe multiple caretaking and attachment. In J. L. Gewirtz \& W. M. Kurtines (Eds.), Intersections with attachment (pp. 41-51). Hillsdale, NJ: Erlbaum.

Murray, H. A. (1943). Thematic Apperception Test manual. Cambridge, MA: Harvard University Press.

Nathan, M. (1984). Lina meshutefet - Lina mishpahtit, takzirei vesikoumei mechkarim [Communal versus familial children's sleeping arrangement: Abstract and summaries of studies]. Yediot (15). Oranim, Israel: Institute for Research on Collective Education.

Ophir-Cohen, M., Epstein, R., Tzischinsky, O., Tirosh, E., \& Lavie, P. (in press). Sleep patterns of children sleeping in residential care, in kibbutz dormitories and at home-A comparative study. Sleep.

Oppenheim, D., Sagi, A., \& Lamb, M. E. (1988). Infant-adult attachments on the kibbutz and their relation to socioemotional development 4 years later. Developmental Psychology, 24, 427-433.

Palgi, M., Blasi, J. R., Rosner, M., \& Safir, M. (Eds.). (1983). Sexual equality: The Israeli kibbutz tests the theories. Norwood, PA: Norwood.

Phillips, D. A., \& Howes, C. (1987). Indicators of quality in child care: Review of research. In D. A. Phillips (Ed.), Quality in child care: What does research tell us? (pp. 1-20). Washington, DC: National Association for the Education of Young Children.

Piaget, J. (1959). The language and thought of the child. London: Routledge \& Kagan.

Rabin, A. I. (1958). Infants and children under conditions of "intermittent" mothering in the kibbutz. American Journal of Orthopsychiatry, 28, 576-586.

Rabin, A. I. (1965). Growing up in the kibbutz. New York: Springer

Rabin, A. I., \& Beit-Hallahmi, B. (1982). Twenty years later. New York: Springer.

Rapaport, D. (1958). The study of kibbutz education and its bearing on the theory of development. American Journal of Orthopsychiatry, 28, 587-597.

Regev, E., Beit-Hallhami, B., \& Sharabany, R. (1980). Affective expression in kibbutz-communal, kibbutz-familial, and city-raised children in Israel. Child Development, 51, 223-237.

Richman, C. L. (1990, May). Factors related to the prosocial development of kibbutz children. Paper presented at the meeting of the American Psychological Society, Dallas, TX.

Rosenthal, M. (1991). Daily experiences of toddlers in three child care settings in Israel. Child and Youth Care Forum, 20, 37-58.

Ross, H. S., Conant, C., Cheyne, J. A., \& Alevizos, E. (1992). Relationships and alliances in the social interaction of kibbutz toddler. Social Development, 1, 1-16.

Sacks, J. M., \& Levy, S. (1950). The sentence completion test. In L. E. Abt \& L. Bellak (Eds.), Projective psychology (pp. 357-402). New York: Knopf.

Sadeh, A., Lavie, P., Scher, A., Tirosh, E., \& Epstein, R. (1991). Actigraphic home monitoring of sleep-disturbed and control infants and young children: A new method for pediatric assessment of sleepwake patterns. Pediatrics, 87, 494-499.

Sagi, A. (1990). Attachment theory and research from a cross-cultural perspective. Human Development, 33, 10-22.

Sagi, A., Aviezer, O., Joels, T., Koren-Karie, N., Mayseless, O., Sharf, M., \& Van IJzendoorn, M. H. (1992, July). The correspondence of mother's adult attachment with infant-mother attachment relationship in traditional and non-traditional kibbutzim. Paper presented at the XXV International Congress of Psychology, Brussels, Belgium.

Sagi, A., Koren, N., \& Weinberg, M. (1987). Fathers in Israel. In M. E. Lamb (Ed.), The father's role: Cross-cultural perspectives (pp. 197226). Hillsdale, NJ: Erlbaum. 
Sagi, A., \& Koren-Karie, N. (1993). Day-care centers in Israel: An overview. In M. Cochran (Ed.), International handbook of day-care policies and programs (pp. 269-290). New York: Greenwood Press.

Sagi, A., Lamb, M. E., Lewkowicz, K., Shoham, R., Dvir, R., \& Estes, D. (1985). Security of infant-mother, -father, and -metapelet attachments among kibbutz-reared Israeli children. Monographs of the Society for Research in Child Development, 50(1-2, Serial No. 209).

Sagi, A., Lamb, M. E., Shoham, R., Dvir, R., \& Lewkowicz, K. (1985). Parent-infant interaction in families on Israeli kibbutzim. International Journal of Behavioral Development, 8, 273-284.

Sagi, A., \& Van IJzendoorn, M. H. (in press). Multiple caregiving environments: The kibbutz experience. In S. Harel \& J. P. Shonkoff (Eds.), Early childhood interventıon and family support programs: ACcomplishments and challenges Baltimore: Paul $\mathrm{H}$. Brooks.

Sagi, A., Van IJzendoorn, M. H., Aviezer, O., Donnell, F., \& Mayseless, $O$. (in press). Sleeping away from home in a kibbutz communal arrangement: It makes a difference for infant-mother attachment. Child Development.

Sagi, A., Van IJzendoorn, M. H., \& Koren-Karie, N. (1991). Primary appraisal of the strange situation: A cross-cultural analysis of the preseparation episodes. Developmental Psychology, 27, 587-596.

Selier, F. J. M. (1977). Kibboetz, gezin en gelijkheidsideaal [Kibbutz, family and the ideal of equality]. Assen, The Netherlands: Van Gorcum.

Shamai, S. (1992). Patterns of paternal involvement in the kibbutz: The role of fathers in intact families in the education of their preadolescent children. Unpublished master's thesis, Haifa University, Haifa, Israel.

Shepher, J. (1971). Mate selection among second generation kibbutz adolescents and adults: Incest avoidance and negative imprinting. $A r-$ chives of Sexual Behavior, 1, 293-307.

Spiro, M. E. (1958). Children of the kibbutz. Cambridge, MA: Harvard University Press.

Spiro, M. E. (1979). Gender and culture: Kibbutz women revisited. Durham, NC: Duke University Press.

Spitz, R. A. (1946). Hospitalism: A follow-up report. In The psychoanalytıc study of the child (Vol. 2, pp. 113-117). Madison, CT: International Universities Press.

Spitz, R. A. (1965). The first year of life: A psychoanalytic study of deviant object relations. Madison, CT: International Universities Press.

Sroufe, L. A. (1985). Attachment classification from the perspective of infant-caregiver relationships and infant temperament. Child Development, 56, 1-14.

Sroufe, L. A., \& Fleeson, J. (1986). Attachment and the construction of relationships. In W. Hartup \& Z. Rubin (Eds.), Relationships and development (pp. 51-71). Hillsdale, NJ: Erlbaum.

Steele, M., Steele, H., \& Fonagy, P. (1993, August). Associations among attachment classifications of mothers, fathers, and their infants: Evi- dence for a relationship-specific perspective. Paper presented at the 4th European Conference on Developmental Psychology, Bonn.

Tavecchio, L. W. C., \& Van IJzendoorn, M. H. (Eds.). (1987). Attachment in social networks. Amsterdam: Elsevier.

Tiger, L., \& Shepher, J. (1975). Women in the kibbutz. San Diego, CA: Harcourt Brace Jovanovich.

Tronick, E. Z., Winn, S., \& Morelli, G. A. (1985). Multiple caretaking in the context of human evolution: Why don't the Efe know the Western prescription for child care? In M. Reite \& T. Field (Eds.), The psychology of attachment and separation (pp. 293-322). San Diego, CA: Academic Press.

Van IJzendoorn, M. H. (1990). Developments in cross-cultural research on attachment: Some methodological notes. Human Development, 33, 3-9.

Van IJzendoorn, M. H., \& Bakermans-Kranenburg, M. J. (in press). Attachment representations in mothers, fathers, and clinical groups: A meta-analytic search for normative data. Journal of Consulting and Clinical Psychology.

Van IJzendoorn, M. H., Goldberg, S., Kroonenberg, P. M., \& Frenkel, O. J. (1992). The relative effects of maternal and child problems on the quality of attachment: A meta-analysis of attachment in clinical samples. Child Development, 63, 840-858.

Van IJzendoorn, M. H., \& Kroonenberg, P. M. (1988). Cross-cultural patterns of attachment: A meta-analysis of the strange situation. Child Development, 59, 147-156.

Van IJzendoorn, M. H., Sagi, A., \& Lambermon, M. W. (1992). The multiple caretaker paradox: Some data from Holland and Israel. New Directions in Child Development, 57, 5-24.

Weigl, I., \& Weber, C. (1991). Day care for young children in the German Democratic Republic. In E. C. Melhuish \& P. Moss (Eds.), Day care for young children (pp. 46-55). London: Tavistock.

Weinbaum, E. (1990, August). Family and kibbutz child-rearing effects on emotional moderation. Paper presented at the 98th Annual Convention of the American Psychological Association, Boston, MA.

Whitebook, M., Howes, C., \& Phillips, D. (1989). Who cares? Child care teachers and the quality of care in America: The national child care staffing study. Oakland, CA: Child Care Employee Project.

Winograd, M. (1958). The development of the young child in a collective settlement. American Journal of Orthopsychiatry, 28, 557-562.

Zaslow, M. (1980). Relationships among peers in kibbutz toddler groups. Child Psychiatry and Human Development, 10, 178-189.

Zellermayer, J., \& Marcus, J. (1971). Kibbutz adolescents: Relevance to personality development theory. Journal of Youth and Adolescence, 1 , 143-153.

Received March 10, 1993

Revision received November 29, 1993

Accepted November 30, 1993 